\title{
Immune Response in Human Pathology: Infections Caused by Bacteria, Viruses, Fungi, and Parasites
}

\author{
Jan Verhoef, Kok van Kessel, and Harm Snippe
}

\subsection{Infections}

In the middle of the nineteenth century, it became clear that micro-organisms could cause disease. Effective treatment, however, was not possible at that time; prevention and spread of infectious diseases depended solely on proper hygienic means. At the beginning of the twentieth century, passive and active vaccination procedures were developed against a number of these PATHOGENIC MICRO-ORGANISMS to prevent the diseases in question (rabies, diphtheria, tetanus, etc.). Thanks to the discovery of antimicrobial chemicals (by Paul Ehrlich) and antibiotics (by Sir Alexander Fleming), the threat of infectious diseases seemed to be minimised. Large-scale vaccination programmes against childhood diseases (diphtheria, whooping cough, and polio), started in the early 1950s, raised hopes of finally being able to eradicate these diseases from the planet. This approach was successful for smallpox (1980). However, new infectious diseases have emerged [e.g., Legionella, HUMAN IMMUNODEFICIENCY VIRUS (HIV), Helicobacter, SARS, etc.], and

Final manuscript submitted on March 10, 2017.

J. Verhoef $\cdot$ K. van Kessel $(\bowtie) \cdot$ H. Snippe

Department of Medical Microbiology, University

Medical Center Utrecht, Utrecht University, Utrecht,

The Netherlands

e-mail: k.kessel@umcutrecht.nl

(C) Springer International Publishing AG 2019

M. J. Parnham et al. (eds.), Nijkamp and Parnham's Principles of Immunopharmacology,

https://doi.org/10.1007/978-3-030-10811-3_10 new vaccines and antibiotics are needed. Furthermore, due to intensive medical treatment with antibiotics and immunosuppressive drugs, hospital infections are a growing problem. Bacteria hitherto deemed harmless are causing OPPORTUNISTIC INFECTIONS in immunocompromised patients. The pathogens have developed resistance to many antibiotics, and sometimes no effective antibiotics are available to treat these patients.

To make the story even more serious, man is surrounded and populated by a large number of different non-PATHOGENIC MICROORGANISMS. In the normal, healthy situation, there is a balance between the offensive capabilities of micro-organisms and the defences of the human body. The body's defences are based on vital non-specific and specific immunological defence mechanisms. An infection means that the micro-organism has succeeded in penetrating those lines of defence, signalling a partial or complete breakdown of the body's defence system.

\subsection{Natural Resistance}

The body's FIRST LINE OF DEFENCE comprises the intact cell layers of skin and mucous membrane, which form a physical barrier. The skin's low pH level and bactericidal fatty acids enhance the protection provided by this physical barrier. The defences in the respiratory tract and the gastrointestinal tract are mucus, the 'ciliary elevator' of the epithelium, and the motility of 
the small intestine. The presence of normal microbial flora (colonisation resistance) in the intestine also plays a role in protection against colonisation by external bacteria.

The most important humoral NATURAL resistance factors are complement, ANTIMICROBIAL PEPTIDES, LYSOZYME, interferon, and a number of CYTOKINES (see Chaps. 6 and 8). ANTIMICROBIAL PEPTIDES are widely expressed as part of the professional phagocyte antimicrobial arsenal and rapidly induced at epithelial surfaces. They are found in mammals, invertebrates, and plants. In general, they are small, amphipathic molecules, contain positive charge, and can be structurally divided into several categories. The mode of action goes beyond their antimicrobial capacities, and they elicit a complex array of responses in different cell types. The most extensively studied mammalian gene families are the cathelicidins and DEFENSINS. In general the ANTIMICROBIAL PEPTIDES disrupt lipid membranes and thereby induce microbial killing. Micro-organisms have developed several countermeasures against ANTIMICROBIAL PEPTIDES, but the many structurally different peptide classes still provide protection against infection (Table 10.1).

LYSOZYME, which is found in almost all body fluids, degrades sections of the cell wall of Gram-positive and-in combination with complement-Gram-negative bacteria. This causes the otherwise sturdy cell wall to leak and the bacterium to burst.

Interferons are glycoproteins and may inhibit the replication of viruses. Within several hours after the onset of a virus infection, INTERFERONS are produced in the infected cell and help protect the neighbouring unaffected cells against infection. This protection is brief, but high concentrations of INTERFERONS are produced at a time when the primary immunological response is relatively ineffective.

CYTOKINES, such as INTERLEUKIN-2 (IL-2), granulocyte-macrophage colonystimulating factor (GM-CSF), and tumour necrosis factor- $\alpha(\mathrm{TNF}-\alpha)$, stimulate non-specifically

Table 10.1 Some examples of important human pathogens

\begin{tabular}{|c|c|c|c|}
\hline & Species & Disease/location & Treatment/prevention \\
\hline \multirow[t]{9}{*}{ Bacterium } & $\begin{array}{l}\text { Streptococcus } \\
\text { pneumoniae }\end{array}$ & Pneumoniae/meningitis & Antibiotics/vaccination \\
\hline & $\begin{array}{l}\text { Mycobacterium } \\
\text { tuberculosis }\end{array}$ & Lung tuberculosis & Antibiotics \\
\hline & Vibrio cholerae & Severe diarrhoea & Antibiotics/liquid suppletion/sanitation \\
\hline & $\begin{array}{l}\text { Staphylococcus aureus } \\
\text { MRSA }\end{array}$ & $\begin{array}{l}\text { Wound infection/hospital } \\
\text { infection }\end{array}$ & $\begin{array}{l}\text { Antibiotics, MRSA not sensitive for standard } \\
\text { antibiotics, difficult to treat }\end{array}$ \\
\hline & Neisseria meningitidis & Meningitis & Antibiotics/vaccination \\
\hline & Bacillus anthracis & Systemic infection (sepsis) & Antibiotics as early as possible \\
\hline & $\begin{array}{l}\text { Corynebacterium } \\
\text { diphtheriae }\end{array}$ & Throat/heart & Antiserum, vaccination \\
\hline & Campylobacter jejuni & Intestinal infections & Hygiene, especially food (chicken) \\
\hline & Helicobacter pylori & Gastritis, ulcer & Antibiotics \\
\hline \multirow{4}{*}{$\begin{array}{l}\text { DNA } \\
\text { virus }\end{array}$} & Poxviridae & Smallpox & Vaccination, eradication \\
\hline & Herpesviridae & Herpes genitalis & Antiviral agents \\
\hline & Papovaviridae & $\begin{array}{l}\text { Warts and cervical } \\
\text { carcinoma }\end{array}$ & Surgery \\
\hline & Hepadnaviridae & Hepatitis B & Vaccination \\
\hline \multirow{4}{*}{$\begin{array}{l}\text { RNA } \\
\text { virus }\end{array}$} & Orthomyxoviridae & Influenza & Vaccination \\
\hline & Coronaviridae & SARS & Unknown \\
\hline & Retroviridae & AIDS & Antiviral agents \\
\hline & Caliciviridae & Gastrointestinal infection & Sanitation, hygiene \\
\hline \multirow[t]{3}{*}{ Parasites } & Plasmodium species & Malaria & Prophylactic medication, antimalarial drugs \\
\hline & Giardia species & Intestinal tract & Hygiene \\
\hline & Trypanosoma cruzi & Sleeping sickness & Antiparasitic agents \\
\hline
\end{tabular}


the proliferation, maturation, and function of the cells involved in defence (see Chap. A6).

Innate immune cells recognise microbes by TOLL-LIKE RECEPTORS (TLR) (see section Pathogenesis of SHOCK), giving rise to the above production of CYTOKINES in the early phase of the response.

Micro-organisms that succeed in penetrating the FIRST LINE OF DEFENCE are ingested, killed, and degraded by phagocytic cells [POLYMORPHONUCLEAR LEUKOCYTES (PMN) or NEUTROPHILS, MONOCYTES, and MACROPHAGES], which are attracted to a microbial infection through CHEMOTAXIS. The ingestion by phagocytic cells of the microorganism is enhanced by serum proteins (opsonins), such as ANTIBODIES and the C3b component of complement, which are recognised by specific RECEPTORS on the PHAGOCYTES. After ingestion, the particle is surrounded by the membrane of the phagocyte, forming a vacuole known as a PHAGOSOME. The PHAGOSOME then fuses with some of the countless granules in the phagocyte, thus allowing the lysosomal microbicidal agents and enzymes to do their work. The formation of toxic oxygen radicals greatly contributes to the killing and elimination of the ingested micro-organism (Fig. 10.1) (see Chap. 8).
A special role in cellular NATURAL resistance is reserved for the NATURAL KILLER CELLS (NK cells), which display considerable CYTOTOXIC activity against virus-infected cells. This NK activity is stimulated by INTERFERONS and, at a very early stage in the infection, serves to reinforce the non-specific defence mechanism.

\subsection{Specific Resistance}

In the specific immune response, elements of the NATURAL defence mechanism are directed against a specific enemy. Depending on the micro-organism, either the cellular defence mechanism (tuberculosis) or the humoral ANTIBODY-dependent defence mechanism (influenza) is of primary importance. In many cases, a joint cellular and humoral response is needed to provide an effective immune defence (typhus).

Both $\mathrm{T}$ LYMPHOCYTES and MACROPHAGES play a role in cellular defence. During the first contact with an antigen, MACROPHAGES process the antigen and present its protein fragments (T-cell EPITOPES) to T cells, which then proliferate and remain present for years in the body as memory cells. When a second
Fig. 10.1 Schematic representation of the progressive steps of phagocytic endocytosis

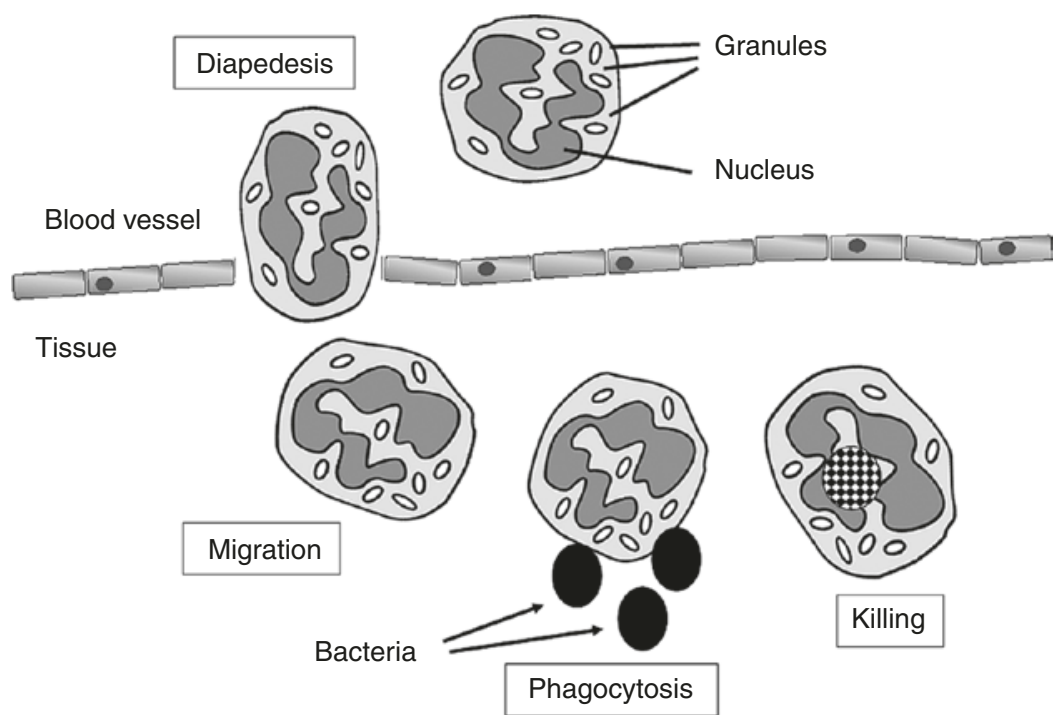


encounter occurs, $\mathrm{T}$ cells produce lymphokines, which activate the MACROPHAGES. These activated MACROPHAGES grow larger, produce more and better degrading enzymes, and are now able to eliminate micro-organisms, which otherwise would have survived intracellularly (tuberculosis, typhoid fever). MACROPHAGES from non-immune animals are not able to eliminate these micro-organisms.

Five different classes of ANTIBODIES can be distinguished in man, namely, IgG, IgA, IgM, $\mathrm{IgD}$, and IgE. They differ from one another in size, charge, amino acid composition, and glycosylation (see Chap. 4). In principle, the structure of the ANTIBODIES is the same, i.e. two heavy and two light chains: it is the variable part of these chains that recognises the micro-organism. The biological function (see below) is determined by the constant part $(\mathrm{Fc})$ of the heavy chain. With the exception of IgD, all these ANTIBODIES are important in antimicrobial activity.

- $\operatorname{Ig} \mathrm{A}$, which is found in all external secretions, reacts with the surface of micro-organisms, preventing them from adhering to sensitive cells and mucous membranes.

- IgG neutralises microbial toxins.

- $\mathrm{IgG}, \mathrm{IgM}$, and $\mathrm{C} 3 \mathrm{~b}$ serve as opsonins, which promote phagocytosis.

- $\operatorname{IgG}, \operatorname{IgM}$, and to a lesser extent IgA activate the complement system after binding to the micro-organism. Activation products $\mathrm{C} 3 \mathrm{a}$ and C5a ensure that the phagocytes are attracted to the inflammatory response.

- IgG and IgM, in combination with complement and lysozyme, have a lytic effect on Gram-negative bacteria and enveloped viruses.

- IgG and IgM inhibit the mobility of microorganisms by attaching specifically to the flagellum. Thereby the chance of phagocytosis increases, and the chance of spreading of disease decreases.

- $\mathrm{IgG}$, together with the killer or $\mathrm{K}$ cells, can eliminate infected host cells which carry viral or other foreign antigens on their surface.

- $\operatorname{IgE}$ is of importance in parasite infections. At the site of the infection, mast cells, bearing specific IgE, release large quantities of vaso- active amines, which cause the contraction of smooth muscle tissue and increase the permeability of the blood vessels. In the intestine, this results in worms being detached and eliminated.

\subsection{Defence Against Bacteria, Viruses, Fungi, and Parasites}

Several non-invasive bacteria, i.e. those that do not invade the body, cause disease through the production of EXOTOXINS (tetanus, diphtheria, cholera). The IMMUNE SYSTEM neutralises the toxin with the aid of ANTIBODIES (IgG, $\operatorname{IgM})$. If the individual has not been inoculated, the toxin will act on certain cells in the body directly through a RECEPTOR. This bond is very strong (i.e. has a high AFFINITY) and is difficult to break by the administration of ANTIBODIES. In practice, if there are clinical symptoms of the disease, then large doses of antitoxins must be administered. If one is trying to prevent the development of the disease, then the presence of small quantities of specific ANTIBODIES (IgG) is sufficient.

The ADHERENCE of bacteria to cells is effectively blocked by $\operatorname{IgA}$. Oral vaccination against cholera, for example, is aimed at obtaining sufficient specific IgA in the intestine, so that no colonisation of this bacterium can take place and the cholera toxin can no longer adhere to its RECEPTOR.

In general, defence against invasive bacteria is provided by ANTIBODIES (IgG, IgM) that are directed against bacterial surface ANTIGENS. In many cases, these bacteria have a CAPSULE, which interferes with effective PHAGOCYTOSIS. ANTIBODIES against the ANTIGENS of these capsules neutralise the interference, with subsequent elimination of the bacteria by PHAGOCYTES. ANTIBODIES ( $\operatorname{IgM}, \operatorname{IgG}, \operatorname{IgA}$ ) in combined action with complement kill bacteria by producing holes in the cell wall of the bacterium.

Although intracellular bacteria (tuberculosis, leprosy, listeriosis, brucellosis, legionellosis, and salmonellosis) are ingested by MACROPHAGES, 
they are able to survive and multiply. In these cases, cellular immunity alone provides the defence, since ANTIBODIES are not effective. Only activated MACROPHAGES are capable of killing and degrading these bacteria.

ANTIBODIES neutralise viruses directly and/ or indirectly by destroying infected cells that carry the virus antigen on their surface. The mechanisms of this defence resemble those of humoral defence against bacterial surfaces. The ANTIBODYdependent cellular CYTOTOXICITY reaction is specific for defence against viruses. Cells that carry an antigen encoded by the virus on their surface are attacked by CYTOTOXIC K cells, bearing ANTIBODIES that fit the antigen on the TARGET cell ( $\mathrm{K}$ cells have Fc RECEPTORS for IgG) (Fig. 10.2).

Not only humoral but also cellular immunity plays an important role in virus infections. People with a genetic T-cell deficiency are highly susceptible to virus infections. In cellular defence, it is primarily the virus-infected cells that are attacked and eliminated. CYTOTOXIC $\mathrm{T}$ cells recognise MHC class I-presented T-cell EPITOPES on the surface of virus-infected cells and kill them.

The fungi responsible for human diseases can be divided into two major groups on the basis of

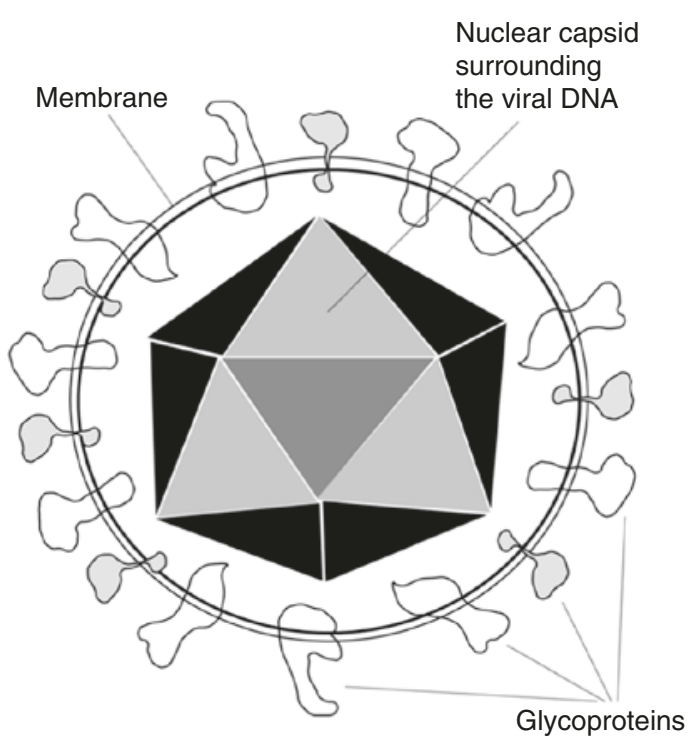

Fig. 10.2 Schematic illustration of an enveloped virus (Herpes simplex virus) their growth forms or on the type of infection they cause. Pathogens exist as branched filamentous forms or as yeasts, although some show both growth forms. The filamentous types (Trichophyton) form a 'mycelium'. In asexual reproduction, the fungus is dispersed by means of spores; the spores are a common cause of infection after inhalation. In yeast-like types (Cryptococcus), the characteristic form is the single cell, which reproduces by division or budding. Dimorphic types (Histoplasma) form a mycelium outside but occur as yeast cells inside the body. Candida shows the reverse condition and forms a mycelium within the body.

In superficial mycoses, the fungus grows on the body surface, for example, skin, hair, and nails (Epidermophyton, Trichophyton), the disease is mild, and the pathogen is spread by direct contact. In deep mycoses (Aspergillus, Candida, Cryptococcus, Histoplasma), internal organs are involved, and the disease can be life-threatening and is often the result of opportunistic growth in individuals with impaired immunocompetence.

Many of the fungi that cause disease are freeliving organisms and are acquired by inhalation or by entry through wounds. Some exist as part of the normal body flora (Candida) and are innocuous unless the body's defences are compromised in some way. The filamentous forms grow extracellularly, while yeasts can survive and multiply within phagocytic cells. NEUTROPHILS kill yeasts by means of both intra- and extracellular factors. Some yeasts (Cryptococcus neoformans) form a thick polysaccharide CAPSULE to prevent phagocytic uptake. In addition, many cellwall components of yeasts cause suppression of cell-mediated immune responses. The role of humoral and cellular immunity in controlling infections caused by fungi is not yet well defined, but cellular immunity is the cornerstone of host defence against (some) fungal infections. As a consequence, HIV INFECTION, which affects the cellular arm of the IMMUNE SYSTEM, results in previously uncommon infections such as those caused by $C$. neoformans.

The immunological defence systems against parasites are considerably more complex than those against bacteria and viruses. This is due to 
various factors. In the first place, each parasite has its own life cycle, consisting of various stages with specific antigen compositions. Moreover, parasites are able to avoid the host defence system (mimicry), to combat it (IMMUNOSUPPRESSION), or to mislead it (antigenic variation). Both humoral and cellular immunity are important for the defence against parasites growing intercellularly, as we have seen in the case of bacteria and viruses. ANTIBODY concentrations (IgM, IgG, IgE) are often elevated. IgE also plays a special role in the removal of parasites (especially worm infections) from the intestine (see above) (Table 10.2).

\section{Table 10.2 Classification of micro-organisms}

\section{Classification of bacteria by:}

Genotypical characteristics: chromosomal DNA fragment analysis, nucleic acid sequence analysis, probes

Phenotypical characteristics: morphology, biotyping, serotyping, antibiotic resistance

Analytical characteristics: cell-wall analysis, lipid and protein analysis, enzyme typing (catalase)

Gram staining positive or negative

Aerobic, anaerobic: Fermentation of different sugars

Naming and classification of viruses according to:

Structure: size, morphology (naked, enveloped), nucleic acid (RNA, DNA)

Molecular aspects: mode of replication, assembly, and budding

Disease: encephalitis, hepatitis

Means of transmission: droplets, water, blood, insects

Host range: animal, plant, bacteria

Classification of fungi according to:

Structure: macroscopic morphology of hyphae (mycelium); microscopic morphology of hyphae, conidiophores and conidia (spores); and shape and size Cell features: nucleus, cytosol, plasmalemma (cell membrane which contains cholesterol), physiology, staining properties

Sexual characteristics: sexual and/or asexual reproduction, extended dikaryotic phase, basidium formation

Genotypical characteristics: chromosomal DNA fragment analysis, nucleic acid sequence analysis, probes

Diagnosis of parasites by:

Macroscopical examination

Concentration of cysts and eggs by microscopic examination

Serological diagnosis: antibody response

Detection of parasite by serology and by nucleic acid hybridisation: probes and amplification techniques

\subsection{Pathogenesis of Shock}

Sepsis is a systemic inflammatory response to presumed or known infection (see also Chap. 26). The resulting inflammatory response becomes over amplified, leading to multiple organ failure and death. PATHOGEN-ASSOCIATED MOLECULAR PATTERNS (PAMP) in bacteria, viruses, parasites, and fungi initiate the host response by triggering families of PATTERN RECOGNITION RECEPTORS (PRR). In Gramnegative (Fig. 10.3) bacterial infections, the interaction between bacterial ENDOTOXIN or LIPOPOLYSACCHARIDE (LPS; a major structural component of the cell wall) and various host-cell systems has been implicated in the pathogenesis of septic SHOCK. In particular, the release of TNF- $\alpha$ and INTERLEUKIN-1 (IL-1) after the activation of host cells by ENDOTOXIN induces haemodynamic SHOCK.

Biochemical and genetic evidence has identified TLR4 as the RECEPTOR that mediates cellular activation in response to LPS. This family of TLR proteins (Fig. 10.4), which resemble the antimicrobial Toll proteins of Drosophila (fruit fly), has been identified in humans and mice. TLR4 was identified as the missing link in LPSinduced cell signal transduction and responsiveness that is associated with MD-2 and CD14. It is known that $\mathrm{C} 3 \mathrm{H} / \mathrm{HeJ}$ mice are hyporesponsive to the biological effects of LPS. This proved to be the result of TLR4 deficiency. The TLR family members are coupled to a signalling adapter protein (MyD88) and form differential dimers that may explain the discrete responses to TLR ligands such as lipoproteins, heat SHOCK proteins, unmethylated $\mathrm{CpG}$ DNA, viral dsRNA, and bacterial flagellin. Intracellular signalling involves several kinases depending on the TLR involved and includes the MAP kinase and NF- $\kappa \mathrm{B}$ pathways leading to a cellular response. PAMP for TLR2 include a variety of agonists derived from Gram-positive organisms such as PEPTIDOGLYCAN and lipoteichoic acid. Therefore, it seems that TLR2 and TLR4 are activated primarily by different PAMP to initiate the host response to Gram-positive and Gramnegative bacterial infection, respectively. This is 
Fig. 10.3 Schematic illustration of the cell envelope of a Gramnegative and a Grampositive bacterium

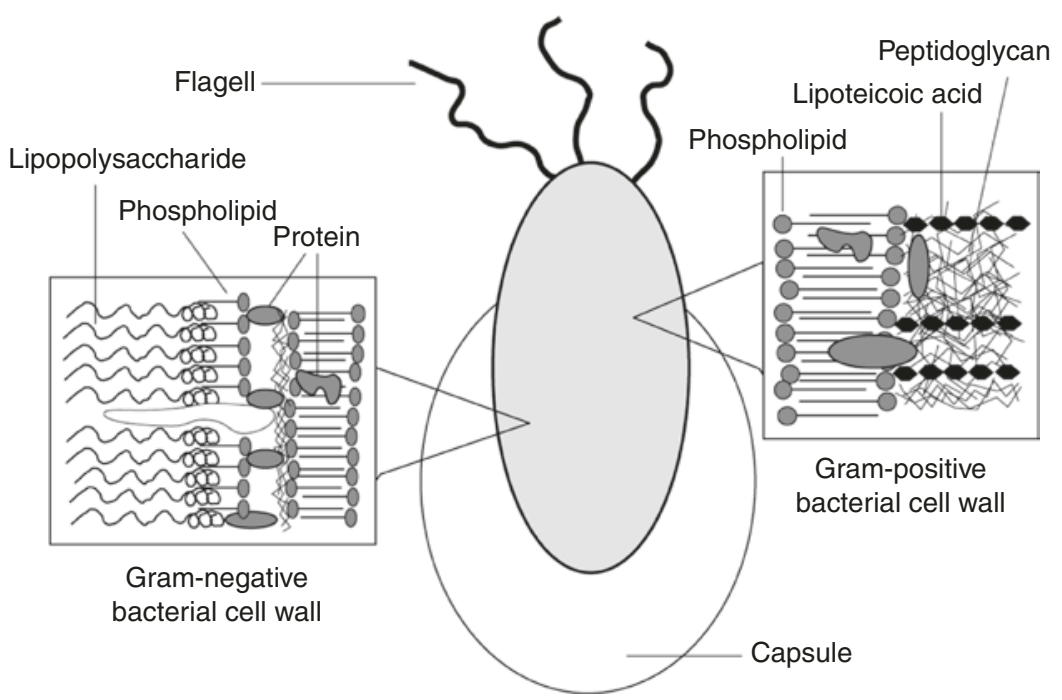

Fig. 10.4 Schematic illustration of cell activation through Toll-like receptors (TLRs)

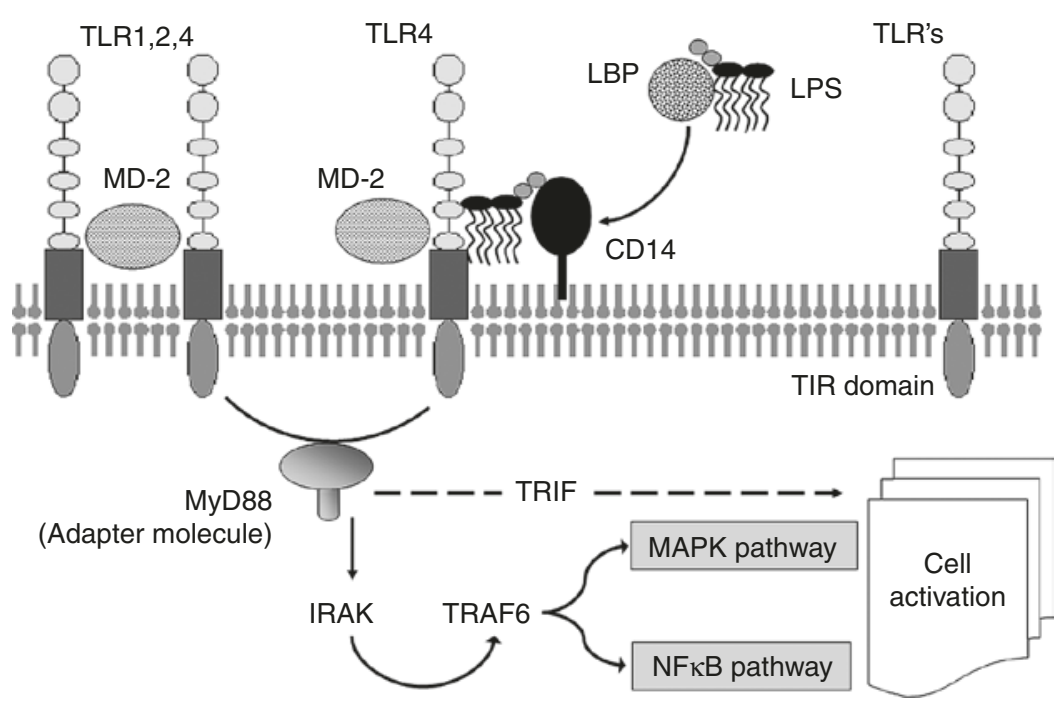

further illustrated by the fact that TLR2 (but not TLR4) knockout mice are highly susceptible to GRAM-POSITIVE BACTERIA, like Staphylococcus aureus, whereas TLR4 (but not TLR2) knockout mice are highly susceptible to Gram-negative bacteria such as Salmonella typhimurium.

Several lines of evidence support the current hypothesis that the monocyte/macrophage is the principal cellular mediator of endotoxicity. LPShyporesponsive TLR4-deficient $\mathrm{C} 3 \mathrm{H} / \mathrm{HeJ}$ mice are made responsive by transfer of MACROPHAGES of a closely related LPSsensitive strain. When the host is challenged with
LPS, soluble factors are produced by MACROPHAGES that mediate fever and an acute-phase response. These factors include the pro-INFLAMMATORY CYTOKINES, IL-1, IL-6, IL-8, and TNF- $\alpha$. Together, TNF- $\alpha$ and IL-1 stimulate endothelial cells to produce and express proteins on their membrane that have adhesive properties for LEUKOCYTES, promoting the margination and passage of neutrophils from blood vessels through the endothelial layer, leading to neutrophil influx into the tissue. ADHESION MOLECULEs that mediate the binding of neutrophils appear on the endothelium after an inflammatory stimulus, followed by 
molecules that are specific for adhesion of MONOCYTES or LYMPHOCYTES, which may be why NEUTROPHILS enter before mononuclear cells. Molecules that are currently known to be involved in leukocyte-endothelium interactions belong to three structural groups: the immunoglobulin gene superfamily, the integrin family, and the selectin family.

Concomitant with cytokine release, LPS induces the activation of neutrophils, MACROPHAGES, and many other cells, resulting in the release of toxic oxygen radicals, which lead to tissue damage. At the same time, membraneassociated phospholipases are activated, and products of the arachidonic acid cascade are released through the CYCLOOXYGENASE and/or LIPOXYGENASE pathways (see Chap. 9). PLATELET-ACTIVATING FACTOR (PAF) is also generated, partly in response to the same signals. All these products contribute to a generalised inflammatory state with influx of neutrophils, capillary-leak syndrome, disturbances in blood coagulation, and myocardial suppression.

ENDOTOXIN and TNF- $\alpha$ also trigger multiple abnormalities in coagulation and fibrinolysis, leading to microvascular clotting and diffuse intravascular coagulation. They also induce endothelial cells to produce plasminogen activator and IL-6, which is an important modulator of the production of acute-phase proteins by the liver. Interestingly, despite having important structural differences, TNF- $\alpha$ and IL- 1 have multiple overlapping and few distinct biological activities, act synergistically, and mimic the whole spectrum of toxicity caused by LPS (see Chap. 6). IL-8 is an important chemoattractant and activator of NEUTROPHILS and is crucial in the early stages of INFLAMMATION.

Infusion of ENDOTOXIN in healthy humans leads to an early and transient increase in plasma levels of TNF- $\alpha$ (detectable after $30 \mathrm{~min}$, peaking after 90-120 min, and undetectable after 4-6 h), which coincides with the development of clinical symptoms and pathophysiological responses encountered in Gram-negative septicaemia. TNF$\alpha$, IL-1, IL-6, and IL-8 levels are also increased in patients with sepsis syndrome, with high levels of these CYTOKINES being correlated with severity of disease.

All these observations support the concept that ENDOTOXIN largely acts by initiating an inflammatory response through the activation of MONOCYTES/MACROPHAGES and the subsequent release of CYTOKINES. It also activates the COMPLEMENT SYSTEM (leading to the generation of $\mathrm{C} 5 \mathrm{a}$, which induces aggregation of neutrophils and pulmonary vasoconstriction) and factor XII of the intrinsic coagulation pathway (Hageman factor). Finally, it induces the release of ENDORPHINS, which are also involved in the complex interactions of the inflammatory response in endotoxic septic SHOCK.

GRAM-POSITIVE BACTERIA are frequently and increasingly cultured from blood obtained from patients in SHOCK. Unlike the pathophysiology of SHOCK caused by Gramnegative bacteria, not much is known about the sequence of events that controls the signalling of MONOCYTES and MACROPHAGES that leads to the release of CYTOKINES. Cell-wall components, such as PEPTIDOGLYCAN and teichoic acid, are clearly important in the activation of these cells. EXOTOXINS, however, may also play a role in the pathogenesis of Gram-positive bacterial SHOCK.

Recently, another protein family was identified that also participates by sensoring microbial components derived from bacterial PEPTIDOGLYCAN. The NOD (NUCLEOTIDEBINDING OLIGOMERISATION DOMAIN) proteins NOD1 and NOD2 have been implicated in intracellular recognition of the core structure, $\gamma$-D-glutamyl-meso-diaminopimelic acid, present in PEPTIDOGLYCAN.

A number of circulating inflammatory mediators have been investigated as marker tools to facilitate the early recognition of sepsis. These include IL-1, IL-6, TNF, pro-calcitonin, and triggering RECEPTOR on myeloid cells (TREM-1). TREM-1 is expressed on LEUKOCYTES, and TREM family members have been implicated in mounting the inflammatory response. Procalcitonin (PCT) and IL-6 have proved to be the most prominent biomarkers of early sepsis. PCT is the prohormone of the hormone calcitonin and 
can be produced by several cell types and many organs in response to pro-inflammatory stimuli, in particular by bacterial products. More recently HIGH MOBILITY GROUP BOX-1 (HMGB-1) has been implicated as a lethal mediator of systemic INFLAMMATION. HMGB-1 is a nuclear and cytosolic protein widely studied as a transcription and growth factor that is released into the extracellular environment. It has a weak proinflammatory activity by itself, and it may work in concert with other pro-INFLAMMATORY CYTOKINES. This molecule may also be useful as a biomarker in the stratification of sepsis.

Susceptibility to sepsis can be influenced by factors that include ethnicity, gender, age, genetic defects, and environmental factors. Single-nucleotide polymorphisms (involving single base-pair alterations) have been described in genes controlling the host response to infection such as alterations in TNF RECEPTORS, IL-1 RECEPTORS, coagulation factors, and TLR. It is now clear that sepsis is a complex, dynamic syndrome with great heterogeneity and not a distinct disease. Therefore, neutralisation of a single key mediator as a cure for all patients with sepsis is erroneous (see Chap. 26).

\subsection{Human Immunodeficiency Virus Infection}

The HIV is a retrovirus that infects cells bearing the CD4 antigen, such as T helper cells (Th), MACROPHAGES, and DENDRITIC CELLS. The CD4 molecule, together with other RECEPTOR molecules, like chemokine RECEPTOR CCR5, acts as a binding site for the gp120 envelope glycoprotein of the virus. In an attempt to respond to HIV ANTIGENS and concomitant secondary microbial infections, these cells are activated, thus inducing the replication of HIV in the infected CD4 T cells, which are finally destroyed. In contrast, HIV-1 infection of MACROPHAGES is self-sustained and results in an inexorable growth of chronic active inflammatory processes in many tissue compartments including the CENTRAL NERVOUS SYSTEM. Infected cells bear the fusion protein gp41 and may therefore fuse with other infected cells. This helps the virus to spread and accounts for the multinucleated cells seen in lymph nodes and brain. As a result of the decreased numbers of $\mathrm{CD} 4^{+}$Th cells and defects in antigen presentation, depressed immune responses in these patients are observed. During the progression of the disease, OPPORTUNISTIC INFECTIONS by otherwise harmless micro-organisms can occur. These include Candida albicans oesophagitis, mucocutaneous herpes simplex, toxoplasma in the CENTRAL NERVOUS SYSTEM, and pneumonia caused by toxoplasma and Pneumocystis carinii; Kaposi's sarcoma also occurs frequently in these patients. This has been linked to the presence of a previously unknown type of herpes virus (HHV-8). This immune deficiency syndrome is called 'acquired immune deficiency syndrome' (AIDS). It has been suggested that infected MONOCYTES/MACROPHAGES carry the HIV virus into the brain where it replicates in microglia and infiltrating MACROPHAGES. As a consequence, many AIDS patients develop cognitive and motor brain impairments. However, the picture is complicated by the various persistent infections already present in these patients, which give rise to their own pathology in the brain. These include Toxoplasma gondii, Cryptococcus neoformans, and JC virus.

So far, no cure for HIV INFECTION has been achieved. The main effort in the prevention of HIV INFECTION lies in mass public education programmes. Treatment of infected individuals is possible but expensive. HIGHLY ACTIVE ANTIRETROVIRAL THERAPY (HAART) reduces morbidity and mortality among patients infected with HIV (see Fig. 10.5). Success is limited by the emergence of drug-resistance viruses that can be transmitted to newly infected individuals. Resistance, drug toxicity, and poor patient ADHERENCE lead to treatment failure and necessitate continuous development of alternative treatment strategies that intervene with the HIV replication cycle: i.e. on the level of virus entry, critical viral enzymes [reverse transcriptase (RT), integrase (IN), and proteases (PR)], or viral nucleocapsid (NC) protein. At this moment a triple therapy is being prescribed in Western countries (two RT inhibitors and one PR inhibitor, 
Fig. 10.5 The effect of single and triple therapy on viral load and CD4 cells over time in HIV-infected individuals

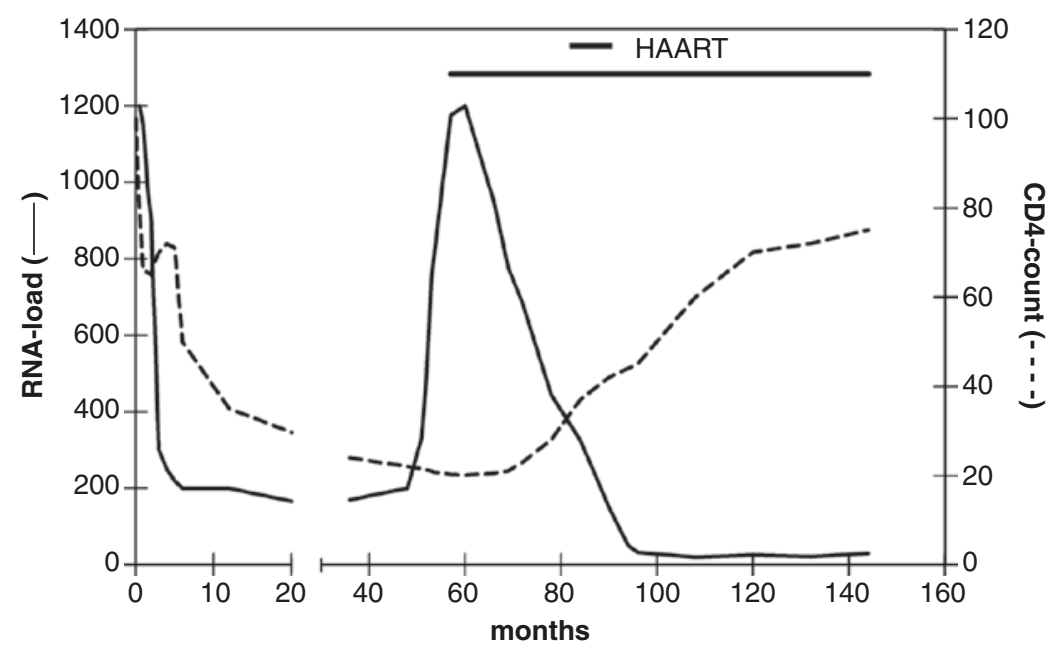

Fig. 10.4), each of which interfere with specific steps in the process of HIV replication. One major problem that has arisen is the increasing resistance to these drugs. Agents with novel MECHANISMS OF ACTION provide options for patients with DRUG-RESISTANT virus. Blocking of the chemokine RECEPTOR CCR5, a co-RECEPTOR on CD4 cells for HIV, is an alternative treatment for persons infected with the R5 HIV type. This notion is supported by a recent finding that a homozygous defect in this chemokine RECEPTOR accounts for resistance of multiple-exposed individuals to HIV-1 infection. Currently a commercially available drug is being used that specifically binds to CCR5 on the surface of the CD4 cell and selectively blocks HIV-1 binding. One remarkable HIV patient, known as the 'Berlin patient' and on an antiretroviral therapy for 10 years, was diagnosed with acute myeloid leukaemia and therefore received a haematopoietic stem cell transplant from a donor with the 'resistant' CCR5 receptor. He had to stop his antiretroviral medication, and after 3 months, the virus was undetectable, and his CD4 counts recovered. He is now considered cured from HIV.

\subsection{Vaccines and Vaccination}

Pasteur and Koch triggered the stormy development of vaccines (anthrax, rabies, cholera) at the end of the nineteenth century. While Pasteur remained faithful to the principle of attenuated micro-organisms in preparing his vaccines, Koch employed killed germs (cholera) as a vaccine. Since diphtheria and tetanus cause disease by means of toxins, the next logical step in the development of vaccines was the use of detoxified toxins to induce protection against these diseases [diphtheria (Von Behring) and tetanus (Kitasato)]. Von Behring and Kitasato were the first to demonstrate that the source of the protective activity induced by vaccines was present in blood serum. Von Behring was also the first to prove that protective immunity could be passed on via serum. The development of new vaccines had its ups (yellow fever) and downs (tuberculosis). With the arrival of antibiotics, all work on new bacterial vaccines was suspended or severely curtailed, although some researchers continued to work on viral vaccines, such as rubella, measles, polio, and mumps.

Since it has proved difficult to consistently develop new antibiotics to combat antibioticresistant bacteria, interest in vaccines has gradually increased over the last 15 years (see Chap. C1). Today, thanks to new insights into the IMMUNE SYSTEM and modern molecular biological and chemical techniques of analysis and synthesis, it is possible to produce well-defined vaccines. These contain only those determinants of the PATHOGENIC MICRO-ORGANISM that induce protection (EPITOPES). These EPITOPES are usually short peptide or oligosaccharide 
chains, which can be produced synthetically or by means of RECOMBINANT DNA techniques. The immunogenicity of these products can be enhanced by coupling them to a CARRIER (tetanus toxoid, liposomes) and/or by adding an adjuvant (a substance that strengthens the immune response non-specifically). The RECOMBINANT DNA technique can also be used to obtain attenuated strains of micro-organisms, which are fully immunogenic and thus provide protection but which are no longer virulent. One example of this is the development of a new cholera vaccine based on a bacterium that has all the characteristics of a virulent strain, except the toxin. The bacterium has retained all its ADHERENCE factors, which allow it to adhere to the intestinal mucosa; the length of time it spends in the intestine is sufficient to stimulate the local IMMUNE SYSTEM. The newest trend in vaccinology is immunisation by introducing plasmid DNA into the host. Success has been attained by this method for hepatitis B vaccination. An example that holds a combination of modern techniques has been developed to combat Malaria, a communicable disease caused by the Plasmodium parasite that is transmitted by female Anopheles mosquitoes. P. falciparum causes the highest rates of complications and mortality and is a serious public health concern in most countries in sub-Saharan Africa, especially young children. Besides many alternative strategies to combat the spread of malaria, vaccination is a long-going approach. A promising candidate vaccine combines the circumsporozoite coat protein fused to hepatitis B surface antigen exposed on the surface of selfassembled virus-like particles together with immunomodulatory adjuvants. It has been shown to induce an immunogenicity profile in controlled human malaria infection model and field studies in sub-Saharan Africa.

Not only are new vaccines being developed, but it is also possible to heighten NATURAL resistance for longer or shorter periods. Various INTERLEUKINS (IL-2, GM-CSF) and INTERFERONS are being studied in order to use them to combat infectious diseases (see Chap. C7). Passive ANTIBODY therapy with polyclonal or MONOCLONAL ANTIBODIES (mouse or human IgG with single SPECIFICITY) for infectious diseases is experiencing a renewed interest. Targeting soluble factors (like neutralisation of bacterial toxins and viruses) or common structures (like bacterial adhesins or viral entry factors) in high-risk patient groups may be beneficial alone or may enhance the therapeutic EFFICACY of other drugs. Targets for clinical development of MONOCLONAL ANTIBODIES include multiresistant staphylococci and enterococci, Bacillus anthracis toxin, HIV, HEPATITIS C VIRUS (HCV), and respiratory syncytial virus (RSV). Therapeutic application of human monoclonal antibodies is boosted by their proven success for various cancers. Molecular cloning and efficient in vitro production by cell lines enable customising antibody properties like IgG subclass, glycosylation pattern (to chance effector functions like complement activation, receptor triggering, or half-life), or coupling with toxins, antibiotics, and inhibitors. Renewed optimism for treatment of HIV is encouraged by uncovered naturally arising, broad, and potent HIV-1neutralising antibodies. It is a challenge to select the best monoclonal antibody (or cocktail) that not only depends on its capacity to recognise HIV broadly, but may also relate to the kinetics of the antibody epitope expression on infected cells. Understanding the molecular complexity of the neutralising antibody repertoire towards the main antigenic determinant of the influenza virus, the HA surface glycoprotein, is important to design a future vaccine that can elicit long-term broadly protective antibodies to a variety of different strains. Combining new adjuvants with current $\mathrm{H} 1 \mathrm{~N} 1$ vaccine improved antibody affinity maturation and offers the promise of improved protection in vivo, particularly in naïve individuals.

The clustered regularly interspaced short palindromic repeats (CRISPR)/CRISPR-associated 9 (Cas9) system is a versatile RNA-guided DNAtargeting platform, which enables efficient and directed manipulation of genomes. It is a bacterial defence mechanism for degradation of foreign nucleic acids of bacteriophages and other genetic elements. This developing platform has been revolutionising our ability to modify and 
manipulate genomes, which profoundly changes biological research and therapeutics development. Targeting in vitro herpesviruses (HSV-1, HCMV, and EBV) with this new editing technique induced complete inhibition of viral replication and even eradication of viral genome from infected cells. Herpesviruses, hepatitis B virus, and HIV are known for their persistence or latency state where they are unrecognisable for the immune system. Therefore the DNA-targeting CRISPR/Cas system could be a powerful tool to tackle persistent viral infections. However, so far the technique proved is value for in vitro cell cultures, while application to the clinic will require a method of safe and efficient delivery.

\subsection{Infections in the New Millennium}

As outlined above for a number of bacteria and viruses, effective vaccines have been developed and applied worldwide. The eradication of smallpox (Variola major) virus in the 1970s was a milestone for the World Health Organisation. The next goal of the WHO is to eradicate poliovirus in the coming years. Major problems to be dealt with are the distribution of these vaccines, the costs involved, the registration and the compliance of the vaccines, and molecular techniques to trace the final bug. Meanwhile new unexpected microbiological threats become in focus. Hospital infections caused by multiresistant microorganism due to the abundance use of antibiotics and exchange of genetic material between microorganisms impose major problems on patients and healthcare workers. New antibiotics and/or vaccines should be developed and new strategies employed to contain these infections. Due to crowding and the high mobility of the world population, old and new pathogens, e.g. influenza and SARS, threaten our society. The recent influenza A H1N1 ('Mexican') flu outbreak in 2009 demonstrated how rapidly a new strain of flu can emerge and spread around the world. The sudden outbreak of this novel flu virus has tested the world's public health preparedness. In the Netherlands, Q fever emerged with large epi- demic outbreaks. Q fever is a zoonotic disease that is passed from infected (farm) animals (cattle, sheep, and goats are the primary carriers) to humans. Q fever is a disease caused by the intracellular bacterium Coxiella burnetii. Organisms are excreted in milk, urine, and faeces of infected animals. Most importantly, during birthing the organisms are shed in high numbers within the amniotic fluids and the placenta. C. burnetii is resistant to heat, drying, and many common disinfectants, allowing it to survive for a long time in the environment. People can become infected by inhalation of the bacteria, but the risk of infection is low. Only about one-half of all people infected with $C$. burnetii show signs of clinical illness (e.g. flu-like illness, pneumonia, and hepatitis). Q fever can be treated with antibiotics, and most people will recover fully. As a control measurement, pregnant goats on dairy farms had to be killed, and a mandatory vaccination campaign was started. Since May 2015, Zika virus infection spread from Brazil to other countries in South and Middle America as well the Western Hemisphere. Although most infections are unnoticed or only follow mild symptoms like fever and rash, in pregnant women, the infection may cause microcephaly. This is a birth defect where a baby's head is smaller than expected and the brain is not developed properly. Zika virus was recently (1947) identified in a rhesus monkey and is spread by the bite of an infected yellow fever or dengue mosquito which are not endemic in the Netherlands. Currently no vaccine or specific medication is available, but new vaccine candidates elicit neutralising antibodies in mice and non-human primates providing protection against Zika virus infection. Since March 2014, the largest outbreak of Ebola virus in history has affected multiple countries in West Africa, especially Guinea and Sierra Leone. Ebola virus causes a grotesque haemorrhagic fever syndrome that is associated with high mortality in humans. The virus originates from an infected animal (like bats) and may jump to a person where it is easily transmitted by direct contact with infected blood or other body fluids. Infected people were placed in quarantine, but the lack of treatment capacity and isolation facilities hampered an efficient 
response. The infection caused major loss of life and socioeconomic disruption in the region. The international community responded with funds, specialists, equipment, and training. Two years later the outbreak has been brought under control, and only an occasional flare-up occurred. The frightening reputation of the disease has reemerged the efforts to produce a vaccine. A recombinant, replication-competent vesicular stomatitis virus-based candidate vaccine, expressing a surface glycoprotein of Zaire ebolavirus, proved to be protective in animals including non-human primates. Although this vaccine candidate was not yet officially approved, an emergency stockpile was produced. A field 'ring vaccination' (after the outbreak) trial proved to be effective in localised infections. This encouraged new opportunities to develop robust and safe new vaccine strategies to combat Ebola virus outbreaks. High-throughput sequencing and epitope mapping, high-resolution proteomics, and single-cell antibody-cloning techniques combined with computational methods are applied to map both natural and elicited epitope targets of antibodies in a given individual. This guides both structural vaccinology approaches and development of protective immunisation with specific human monoclonal antibodies.

Besides developments in vaccinology, highthroughput sequencing (also known as nextgeneration sequencing) methods and computational analysis are becoming widely used to study complex bacterial (and viral) communities in various niches. It is estimated that $90 \%$ of cells in the human body are of microbial origin. This commensal relationship is well established, but the vast majority of the taxa present in the microbiome are unknown. Analysis of the various microbiome populations in the human body (gut, skin, oral cavity, saliva, breast milk, amniotic fluid, as well as from terrestrial and aquatic ecosystems) is just beginning and will shift to biological function in order to get insight in the bidirectional relationship between host and microbiota. The global initiative known as the Human Microbiome Project (started in 2007) aims to catalogue this balance. It is now realised that each person has a unique mix of bacteria and much of the diversity in healthy subjects remains unexplained. Nevertheless, communities of people have distinctive mixes of microbes and communities of microbes associated with a disease may be more or less diverse than controls. It is clear that Koch's postulates, which relate a given infectious disease to a single microbial species, are rarely applied for chronic diseases. Metagenome-wide association studies have demonstrated shifts that are associated with a variety of diseases like obesity, rheumatoid arthritis, and others. The recent advancements also reinforced research for identifying microbes responsible for causing different types of cancers.

On top of this, terrorists might intentionally use micro-organisms (smallpox, anthrax, plague, etc.) or bacterial toxins (botulism) to cause death and disease in humans or animals in a civilian setting. The recognition that an event was caused by a biological weapon presents a severe challenge to be prepared for such an attack, especially for medical care providers and public health officials. Strategies to combat bioterrorism have to be worked out, but with the experience of 100 years of combating micro-organisms with hygiene measures, vaccination, antibiotic, and antiviral treatment, there must be a way out.

\section{Selected Readings}

Arias CA, Murray BE. Antibiotic-resistant bugs in the 21st century - a clinical super-challenge. N Engl J Med. 2009;360:439-43.

Chappell KJ, Watterson D. Fighting ebola: a window for vaccine re-evaluation? PLoS Pathog. 2017;13(1):e1006037.

Franzosa EA, Hsu T, Sirota-Madi A, Shafquat A, AbuAli G, Morgan XC, Huttenhower C. Sequencing and beyond: integrating molecular 'omics' for microbial community profiling. Nat Rev Microbiol. 2015;13(6):360-72.

Henao-Restrepo AM, et al. Efficacy and effectiveness of an rVSV-vectored vaccine in preventing Ebola virus disease: final results from the Guinea ring vaccination, open-label, cluster-randomised trial (Ebola Ça Suffit!). Lancet. 2016;389(10068):505-18.

Hütter G, Nowak D, Mossner M, Ganepola S, Müßig A, Allers K, Schneider T, Hofmann J, Kücherer C, Blau O, Blau IW, Hofmann WK, Thiel E. Long-term control of HIV by CCR5 Delta32/Delta32 stem-cell transplantation. N Engl J Med. 2009;360:692-8. 
Janeway CA, Travers P, Walport M, Shlomchik M. Immunobiology. the immune system in health and disease. New York, NY: Garland Science Publishing; 2001.

Jawetz E, Melnick JL, Adelberg EA, Brooks GF, Butel JS, Ornston LN. Medical microbiology. London: Prentice-Hall International; 2001.

Jiang W, Marraffini LA. CRISPR-cas: new tools for genetic manipulations from bacterial immunity systems. Annu Rev Microbiol. 2015;69:209-28.

Kazmin D, Nakaya HI, Lee EK, Johnson MJ, van der Most $\mathrm{R}$, van den Berg RA, Ballou WR, Jongert E, WilleReece U, Ockenhouse C, Aderem A, Zak DE, Sadoff J, Hendriks J, Wrammert J, Ahmedan R, Pulendran B. Systems analysis of protective immune responses to RTS,S malaria vaccination in humans. Proc Natl Acad Sci U S A. 2017;114:2425-30.

Khurana S, Verma N, Yewdell JW, Hilbert AK, Castellino F, Lattanzi M, Del Giudice G, Rappuoli R, Golding H. MF59 adjuvant enhances diversity and affinity of antibody-mediated immune response to pandemic influenza vaccines. Sci Transl Med. 2011;3(85):85ra48.

Klein F, Mouquet H, Dosenovic P, Scheid JF, Scharf L, Nussenzweig MC. Antibodies in HIV-1 vaccine development and therapy. Science. 2013;341(6151):1199-204.

Mims CA, Playfair JHL, Roitt IM, Wakelin D, Williams R, Anderson RM. Medical microbiology. London: Mosby; 1998.

Montagnier L. 25 years after HIV discovery: prospects for cure and vaccine. Virology. 2010;397:248-54.

Prescott L, Harley J, Klein D. Microbiology. New York, NY: McGraw Hill; 2003.

Rittirsch D, Flierl MA, Ward PA. Harmful molecular mechanisms in sepsis. Nat Rev Immunol. 2008;8:776-8.

Roitt I, Brostoff J, Male D. Immunology. London: Mosby; 2001.

Saylora C, Dadachovaa E, Casadevall A. Monoclonal antibody-based therapies for microbial diseases. Vaccine. 2009;27S:G38-46.

Scheid JF, Horwitz JA, Bar-On Y, Kreider EF, Lu CL, Lorenzi JC, Feldmann A, Braunschweig M, Nogueira L, Oliveira T, Shimeliovich I, Patel R, Burke L, Cohen YZ, Hadrigan S, Settler A, Witmer-Pack M, West AP Jr, Juelg B, Keler T, Hawthorne T, Zingman B, Gulick RM, Pfeifer N, Learn GH, Seaman MS, Bjorkman PJ, Klein F, Schlesinger SJ, Walker BD, Hahn BH,
Nussenzweig MC. HIV-1 antibody 3BNC117 suppresses viral rebound in humans during treatment interruption. Nature. 2016;535(7613):556-60.

Silverstein AM. A history of immunology. San Diego, CA: Academic Press; 1998.

van Belkum A, Melles DC, Nouwen J, van Leeuwen WB, van Wamel W, Vos MC, Wertheim HF, Verbrugh HA. Co-evolutionary aspects of human colonisation and infection by Staphylococcus aureus. Infect Genet Evol. 2009;9:32-47.

van der Poll T, Opal SM. Pathogenesis, treatment, and prevention of pneumococcal pneumonia. Lancet. 2009;374:1543-56.

Wu Y, Yoder A. Chemokine coreceptor signaling in HIV-1 infection and pathogenesis. PLoS Pathog. 2009;5:1-8.

Xiong X, Chen M, Lim WA, Zhao D, Qi LS. CRISPR/ Cas9 for human genome engineering and disease research. Annu Rev Genomics Hum Genet. 2016;17:14.1-14.24.

\section{Important Websites}

\section{Scientific Research}

American Association of Immunology, http://www.aai.org. American Society for Microbiologists, http://www.asm.org. European Federation of Immunological Societies, http:// www.efis.org.

Federation of European Microbiological Societies, http:// www.fems-microbiology.org.

National Library of Medicine, http://www.ncbi.nlm.nih.gov.

\section{Outbreaks of Infectious Diseases}

Centers for Disease Control and Prevention, http://www. cdc.gov.

Daily update: http://www.promedmail.org.

International Society for Infectious Diseases, http://www. isid.org

The Marshall Protocol Knowledge Base, https://mpkb. org/home/pathogenesis/microbiota.

World Health Organisation, http://www.who.int. 